\title{
Argentina, Brasil e Venezuela: as diferentes percepções sobre a construção do Mercosul
}

\author{
Argentina, Brazil and Venezuela: different perceptions \\ about the construction of Mercosul
}

MIRIAM GOMES SARAIVA* JOSÉ BRICEÑO RUIZ**

Rev. Bras. Polít. Int. 52 (1): 149-166 [2009]

\section{Introdução}

Atualmente, o Mercosul é objeto de debate de diversos estudiosos de Integração Regional. A perspectiva de evolução para um mercado comum assinalada no Tratado de Assunção não foi implementada. A entrada da Venezuela como membro pleno, iniciada pela dimensão política, e ainda não concluída, também desperta reflexões. Um elemento importante que limita seu aprofundamento e consolidação diz respeito às percepções e expectativas diferentes que existem sobre o Mercosul no interior de seus Estados-membro perpassando tanto os diplomatas, burocratas de outras agências governamentais, acadêmicos e a sociedade em geral.

Nos casos da Argentina e do Brasil, no decorrer da evolução do processo de integração, foram se desenvolvendo percepções diferentes no interior dos respectivos aparatos governamentais. No caso da Venezuela, com suas especificidades como país amazônico, andino e caribenho, a opção recente por entrar no Mercosul é baseada em uma dinâmica diferente em relação aos vizinhos do sul. ${ }^{1}$

No que diz respeito a Argentina e Brasil, no início dos anos 90, quando é assinado o Tratado de Assunção, suas políticas tanto econômicas quanto externas experimentavam modificações importantes que tiveram impacto sobre o processo de integração. Neste mesmo período, a política externa venezuelana orientava-se mais para a região andina e o Caribe. As relaçôes da Venezuela com os países do Cone Sul limitavam-se acordos

\footnotetext{
* Professora do Programa de Pós-Graduação em Relaçôes Internacionais da Universidade do Estado de Rio de Janeiro - UERJ e pesquisadora do Conselho Nacional de Desenvolvimento Científico e Tecnológico - CNPq (miriamsaraiva@terra.com.br).

** Professor pesquisador do Centro de Estudios de Fronteras e Integración da Universidad de los Andes, Mérida, Venezuela (bricenoruiz@hotmail.com)

1 Em função da candidatura da Venezuela como membro pleno, buscaremos analisar as percepções existentes em seu interior sobre integração regional, assim como as idéias que reorientaram sua política externa para o bloco.
} 
bilaterais de alcance parcial subscritos nos marcos da Associação Latino-Americada de Integração - Aladi.

A chancelaria argentina é mais permeável pela política que o Itamaraty. Historicamente, é muito exposta a pressões de outros setores da política. Os principais atores formuladores e negociadores do processo de integração foram a chancelaria e o Ministério de Economia. No interior de ambos coexistiram perspectivas que tiveram influências sobre a evolução do bloco: no econômico estruturaram-se uma corrente uma ortodoxa e outra heterodoxa, com diferentes enfoques sobre a necessidade e a forma a ser assumida pelo Mercosul; no campo da política, conviveram as visões liberal, pragmática e progressistas. O comportamento do país durante o processo foi marcado também por diferentes interpretações sobre o papel que Brasil deveria jogar no arco de suas relaçóes exteriores

O Itamaraty, por seu turno, é uma corporação forte que historicamente concentra o processo de formulação da política externa. A chegada de Collor de Mello à presidência foi acompanhada de uma crise de paradigma que pôs em xeque os princípios do comportamento externo adotado até então, mas que não levou à consolidação de um novo conjunto de princípios. Levou à divisão basicamente em duas correntes de pensamento - autonomistas e institucionalistas pragmáticos - que influenciaram sobre o avanço do processo de integração. ${ }^{2}$ No entanto, nos primeiros anos do processo estruturou-se uma coalizão interna entre as duas correntes que incluiu as duas correntes (LIMA, 2006). Setores mais favoráveis ao aprofundamento institucional do bloco - os progressistas - virão a ter maior peso somente durante o governo Lula, quando se rompe essa aliança. ${ }^{3}$

Igual que no caso argentino, a chancelaria venezuelana sempre foi muito permeável à forma como se desenvolveu o sistema político do país a partir do fim da ditadura, em 1958. Baseado no Pacto de Punto Fijo, ${ }^{4}$ o sistema político venezuelano teve como fundamento a construção de uma aliança entre as elites que buscou evitar os conflitos, controlar as demandas populares, atender a estas últimas por meio de canais limitados e exercer um controle oligárquico das organizações e canais estabelecidos (CARDOSO DA SILVA, 44). Este marco político determinou em grande medida a política externa que, como parte do sistema puntofijista, sustentou-se em uma aliança entre grupos sociais heterogêneos que reconhecia a legitimidade dos interesses de seus membros e que contava com um sistema de transaçôes e compromissos entre eles. A ascensão ao poder de Hugo Chávez, em 1999, significou mudanças radicais na política venezuelana e na base da sua política exterior.

\footnotetext{
2 Esta definição como institucionalistas pragmáticos é de PINHEIRO (2000) Em geral são definidos como "liberais", mas diferem bastante dos "liberais" argentinos.

3 Malamud e Castro (2007) classificam as percepçōes existentes sobre o Mercosul no Brasil e na Argentina em três grupos: liberais, realistas (aqui pragmáticos) e progressistas.

4 O Pacto de Punto Fijo foi um acordo de governabilidade assinado em 1958 pelos partidos Acción Democrática, Copei e URD, no qual se estabeleceram as regras de funcionamento da democracia venezuelana.
} 
O objetivo deste artigo é analisar as idéias mais marcantes presentes nos atores governamentais de Argentina, Brasil e Venezuela em relação ao Mercosul desde os anos 80 até nossos dias. Para tanto, o artigo será dividido em cinco partes e as considerações finais. A primeira define o fator explicativo aqui adotado. As três partes que se seguem apresentam as percepções do processo de integração que permearam os aparatos governamentais dos três países. A quinta parte dá destaque para as idéias presentes nos governos dos Kirchner, Lula da Silva e Hugo Chávez.

\section{O papel das idéias nos processos de integração regional}

Existem diferentes teorias explicativas para os processos de integração regional. Algumas delas, como o neofuncionalismo ou o intergovernamentalismo, remontam à primeira onda de regionalismo que se desenvolveu entre as décadas de 1950 e 1960. Outras, como a teoria do novo regionalismo ou a aplicação de enfoques construtivistas aos estudos de integração regional, são mais próprios da recente onda regionalista.

As novas experiências regionais são vinculadas, entre outras, à globalização com vistas a atingir um patamar de economia mais aberta, à formação de uma economia de escala com a articulação entre as economias dos países-membro, à defesa dos regimes democráticos, à promoção de mecanismos de governança internacional, e a mecanismos de barganhas estratégicas entre as potências econômicas. No entanto, desde os anos 2000 que estas condições vêm sendo postas em xeque. O modelo de economia aberta vem sendo substituído em diversos países sul-americanos por políticas mais próximas de um neodesenvolvimentismo. Em geral, estas políticas priorizam mais a cooperação que a integração. A idéia de se criar uma economia regional em escala não foi posta em prática até hoje. E o consenso sobre a importância dos regimes democráticos de caráter ocidental perdeu peso em países em desenvolvimento; novas experiências de cunho mais nacionalista orientadas para padrôes diferentes de democracia vêm tendo lugar nestes países. A proliferação de acordos interregionais coloca em xeque a possibilidade de governanças regionais como forma de organização do sistema internacional.

Neste quadro, as explicações mais tradicionais dos processos de integração regional não conseguem proporcionar explicações completas dos processos integração regional fora das fronteiras da Europa. Este artigo propõe avaliar o caso do Mercosul acudindo à análise do papel das idéias sobre as quais se fundamentam as iniciativas de integração.

A importância das idéias nos processos de integração foi desenvolvida, por um lado, por adeptos da abordagem construtivista a partir do trabalho seminal de Alexander Wendt. ${ }^{5}$ Esta abordagem partirá da perspectiva de que, para se

5 Em 1992 Wendt publica o artigo "Anarchy is what state make of it: the social construction of power politics, na revista International Organization n.46, p.391-425, lançando as bases da corrente construtivista nas Relações Internacionais. 
analisar um processo de integração deve-se tomar em conta sua vinculação com as políticas externas dos Estados-membros e os fatores subjetivos que instruem tanto um como o outro.

Vigevani, K. Mariano e M. Mariano (2001, p.11) apontam para a importância da identificação do impacto dos "discursos epistêmicos", oriundos do construtivismo, nos processos de integração regional. Vigevani, Ramazini Jr, Favaron e Correia (2008) chamam a atenção para a necessidade de se entender a posição do Brasil em termos de política externa frente ao Mercosul à luz de fatores cognitivos constitutivos da política exterior, que estão enraizados na sociedade e no Estado brasileiros.

Por outro lado, nos anos 90 Goldstein e Keohane (1993) ressaltaram a partir do institucionalismo racionalista (e com vistas a organizar um padrão explicativo para as idéias) a importância das idéias na formulação de políticas externas. Buscando uma alternativa ao pensamento construtivista neste campo, os autores apontam para 3 tipos de crenças que incidem sobre o comportamento dos formuladores do comportamento de um estado: as visōes de mundo (world views, que criam identidades), as crenças principistas (principled beliefs, crenças baseadas em princípios que têm um caráter normativo) e crenças cuasais (causal beliefs, capazes de gerar causa e efeito). Mais recentemente e Malamud e Schmitter (2006) defendem que as iniciativas de integração requerem como dinâmica de incentivos não somente recompensas materiais, mas também recompensas simbólicas para os países envolvidos.

A visão construtivista sobre o papel das idéias também foi criticada pelos enfoques intergovernamentais. Moravcsik (2001) realizou uma dura crítica à forma como o construtivismo analisa o papel das idéias nas relações internacionais. Uma primeira crítica é que boa parte dos estudos construtivistas partiriam da premissa de que as teorias racionalistas não são capazes de explicar as variaçóes nas identidades e interesses nacionais. Assim, a existência de uma correlação entre "idéias" e "políticas" não seria algo desenvolvido exclusivamente pelos construtivistas. Como assinala Moravcsik (2001, p.229), autonomous shift in ideas are causally epiphenomenal to more fundamental underlying influences on state behavior [...] Ideas are present but not causally central".

Assim, as variáveis "interesse" e "poder" continuam sendo fundamentais para a compreensão dos processos regionais. Um bom número de enfoques nas Relações Internacionais busca embasar a conduta dos atores tanto nas idéias quanto nos interesses. As idéias seriam recursos de poder utilizados por "atores interessados"; o instrumento em lutas políticas que ajudariam certos atores a alcançarem certos objetivos. Pode-se observar que esta abordagem torna as idéias compatíveis com um enfoque de eleição racional, que privilegia por seu turno o papel dos interesses. Neste artigo avalia-se o papel das idéias e as percepçôes sobre o Mercosul, não considerando-as como a variável constitutiva da política de integração, mas sim como um elemento significativo, importante, mas em constante inter-relação com variáveis estruturais de poder ou agenciais de interesse. 


\section{O papel da integração regional na diplomacia argentina: dúvidas e diferenças}

As posições frente ao Mercosul na Argentina caracterizaram-se pela falta de consenso interno sobre a necessidade de se estruturar um espaço regional e, sobretudo, sobre a forma de organizá-lo. A idéia de uma dependência em relação ao Brasil, os riscos de se ter um parceiro imprevisível com uma economia instável, o nacionalismo e a autonomia brasileiros foram sempre temas de debates. As diferenças existentes no interior da chancelaria dificultaram a consolidação de um quadro de referência que orientasse as reflexões sobre a inserção internacional do país e, conseqüentemente, também sobre o processo de integração regional.

Em termos gerais, as visões sobre o Mercosul dividiram-se em três grupos, que tiveram como referência duas correntes de pensamento econômico mais freqüentes no país durante o período. ${ }^{6}$ Em termos estritamente econômicos, os ortodoxos defendem a abertura indiscriminada da economia, e sugerem o desenvolvimento de um menor número de setores produtivos mas que detenham maiores vantagens comparativas e possam ter melhor inserção no mercado internacional. Dão preferência a áreas de livre comércio em detrimento de uniões aduaneiras. Neste caso, os acordos de comércio são julgados pelas suas criações e desvio de comércio, e o quanto o acordo favorece uma maior abertura das economias de seus Estados membros frente ao exterior.

Os heterodoxos, por seu turno, preferem políticas estatais destinadas a promover o desenvolvimento industrial com enfoque setorial. Defendem que a união aduaneira dá aos países-membro acesso preferencial aos mercados do bloco e gera mais benefícios para os parceiros do acordo. No caso do Mercosul, sugerem maior coordenação de políticas macroeconômicas e a introdução de uma agenda industrializante em seu interior. Isto significaria, por um lado, a unificação de posiçōes nas negociações econômicas internacionais tanto nos marcos jurídicos do Mercosul quanto em instâncias multilaterais como as negociaçóes para formação da Alca ou na OMC. Por outro lado, significaria uma integração estratégica de recursos que assegurasse o desenvolvimento dos setores produtivos, junto com a incorporação à agenda do bloco da questão distributiva e de acesso às oportunidades (LAVAGNA, 1997). O fim das assimetrias entendidas como diferenças nas políticas de incentivos para a industrialização seria um passo importante.

Em termos políticos, a primeira visão, a liberal, coincide com a corrente ortodoxa na economia; dá preferência a manter com o Brasil basicamente relaçôes econômicas e busca aproximar-se dos Estados Unidos em termos políticos. Por um lado, esta perspectiva identificou durante os anos 90 o mundo sob o predomínio de uma potência que deveria ser o aliado fundamental. Em seu ponto de vista, o Brasil

6 Sobre as correntes de pensamento econômico, Chudnovsky e López (2000) fornecem elementos interessantes para se entender suas diferenças. 
é identificado como um país com um projeto de liderança individual autônomo que dificulta uma aproximação de posições (RUSSELL e TOKATLIAN, 2003).

Dentre os heterodoxos, encontram-se duas posições diferentes: pragmáticos e progressistas (MALAMUD e CASTRO, 2007). Os pragmáticos defendem um enfoque prioritariamente econômico de um Mercosul que produza benefícios econômicos para o país e onde a institucionalização será bem vinda somente na medida em que aumente sua eficácia neste campo. Têm maior preocupação com o fortalecimento de procedimentos técnicos e com a integração funcional. Os progressistas, por sua vez, têm maior preocupação política. O processo de integração, neste caso, tem uma perspectiva de longo prazo de caráter estratégico vis a vis terceiros Estados. Entendem que o processo de integração fortaleceria a posição da Argentina no concerto de nações. Propõem um Mercosul cuja base seja uma identidade comum no qual a ênfase estaria na participação da sociedade civil e no fortalecimento da parte institucional do bloco, com destaque para instituiçóes como um Parlamento. Isto fortaleceria o desenvolvimento da democracia regional e de uma cidadania mercosulina.

Em relação à possibilidade de uma aliança estratégica com o Brasil, tanto pragmáticos quanto progressistas são favoráveis, mas dando destaque a dimensões diferentes. Ambos apóiam-se na crença da superação definitiva da cultura de rivalidade e na cultura da amizade. Segundo Russell e Tokatlian (2003), o crescimento mais acentuado da economia brasileira junto do conseqüente fim da possibilidade da Argentina implementar uma estratégia de contenção do poder brasileiro através do equilíbrio, a democratização de ambos trazendo maior convergência em valores políticos e uma maior interdependência econômica, favoreceram este novo arranjo regional.

No entanto, seria um elemento a se construir e difícil por tratar-se de uma relação assimétrica onde as partes não têm claro o peso que cada uma delas pode ocupar. $\mathrm{O}$ peso desigual dos dois países no cenário tanto regional quanto internacional, e as numerosas assimetrias existentes em relação à tradição e à eficiência de suas respectivas atuações externas, dificultariam tanto a construção da parceria quanto a formulação de uma posição de consenso dentro da Argentina sobre o tema.

No arco de uma parceria, as visões tanto pragmática quanto progressista propõem um comportamento da Argentina no modelo de Estado barganhador, de acordo com perspectiva de Myers (1991) sobre atuação regional dos Estados. À posição de Estado barganhador, a visão progressista agrega a idéia de uma aliança estratégica para atuação internacional e a importância de uma partilha de valores. Defende uma parceria estável enraizada além do mundo oficial envolvendo agentes econômicos e a sociedade. Neste caso, o Mercosul deveria aprofundar sua institucionalização incluindo as dimensões política e social.

Estas idéias estão presentes entre lideranças políticas, diplomatas, agentes econômicos, assim como intelectuais econômicos e políticos formadores de 
opinião. Encontram-se disseminadas tanto na chancelaria quanto no Ministério de Economia; nem vínculos com um setor específico da burocracia governamental. Não têm um vínculo direto com partidos políticos ou forças políticas organizadas. ${ }^{7}$ Foram opiniōes muitas vezes difusas e em movimento de acordo com a conjuntura.

\section{As visões brasileiras: o peso dos princípios básicos da política externa}

As interpretações existentes no interior da diplomacia e do aparato governamental brasileiros sobre o Mercosul experimentaram tanto diferenças em termos de percepções, quanto, diferentemente do caso argentino, a influência de crenças de longo prazo presentes na política externa brasileira em termos históricos. Segundo Vigevani, Ramazini Jr., Favaron e Correia, a posição do Brasil frente ao Mercosul deve ser vista à luz de dois fatores constitutivos da política externa, enraizados na sociedade e no Estado brasileiros: a autonomia e o universalismo. ${ }^{8}$

Nos marcos destas crenças, em termos político-diplomáticos houve três grupos mais definidos, sendo dois deles mais fortes e com penetração no aparato governamental. Em termos econômicos, é possível separar entre os mais favoráveis a um processo de "liberalização condicionada" (Veiga 2002, 18), e aqueles identificados com o desenvolvimentismo. Apesar do esgotamento do modelo de crescimento baseado na substituição das importações, o êxito do crescimento econômico que o teve como modelo proporcionou a consolidação de setores desenvolvimentistas fortes e estáveis e uma estrutura industrial complexa e diversificada. ${ }^{9}$

A visão mais favorável a uma liberalização condicionada (que não renuncia a política industrializante adotada no período desenvolvimentista), identificava o Mercosul como um espaço para diminuir os impactos e o próprio ritmo de uma abertura para o exterior, e oscilou, nos piores momentos, entre a defesa com pouco vigor do retorno a uma área de livre comércio e a aceitação de uma união aduaneira incompleta. Em termos político-diplomáticos, estes encontraram identidade principalmente nos marcos dos institucionalistas pragmáticos. Este grupo caracterizou-se por, sem abrir mão dos padrões mais profundos da política externa brasileira de autonomia e universalismo, dar maior importância ao apoio do Brasil aos regimes internacionais em vigência. Defende a idéia de uma inserção internacional do país a partir de uma "autonomia pela integração" (onde valores

\footnotetext{
7 Cabe assinalar que a heterodoxia foi mais forte nos governos de Alfonsín (UCR), Duhalde e Kirchner (Partido Justicialista), enquanto a ortodoxia teve força no período de Menem (Justicialista) e um pouco com De la Rúa (UCR).

8 Vigevani, Favaron, Ramanzini Jr. E Correia (2008) fornecem uma boa interpretação para a posição brasileira frente ao Mercosul.

9 O pensamento propriamente liberal no Brasil foi minoritário.
} 
globais devem ser defendidos por todos). Neste caso, busca, na América do Sul, uma liderança mais discreta. ${ }^{10}$ Em relação ao Mercosul, sua visão aproxima-se dos pragmáticos na Argentina: a institucionalização só será bem vinda na medida em que potencialize a capacidade do bloco de produzir benefícios.

Os desenvolvimentistas (que se enquadram nos padrōes da heterodoxia) buscavam a integração como mecanismo de acesso a mercados externos, como impulso para transformações e de maior eficiência no sistema produtivo interno, assim como um canal de projeção e fortalecimento nas negociações econômicas internacionais. Sua maior identidade na esfera diplomática dá-se com a corrente autonomista, que defende uma projeção mais autônoma e ativa do Brasil na política internacional; que teria preocupações de caráter político-estratégico dos problemas Norte/Sul; e que buscaria um papel de maior liderança brasileira na América do Sul. Por perceber a integração sul-americana sob a liderança brasileira como prioridade, considera importante a ampliação do bloco pela entrada de novos Estados. O Mercosul poderia atuar como um instrumento capaz de proporcionar ao Brasil um melhor posicionamento regional, assim como atuar na esfera comercial como elemento capaz de abrir caminho para a formação de uma área de livre comércio na região.

Desde 1991 estas duas abordagens convergiram em torno da formação e evolução do Mercosul. O modelo baseado em uma união aduaneira incompleta, no não-aprofundamento da integração política e no baixo perfil institucional atendeu as diferentes visões. Atuaria como um reforço para a inserção internacional do Brasil, sem os condicionamentos próprios de um mercado comum ou de traços supranacionais. ${ }^{11}$

A perspectiva de uma aliança entre com a Argentina frente aos temas da política regional também foi objeto de consenso entre as duas correntes diplomáticas e outros setores do aparato burocrático brasileiro: a política externa brasileira seria sensível e vista como questão de soberania nacional. Segundo Pinheiro (2000, 323), no caso das relações com países vizinhos o desejo de autonomia "se utiliza da concepção (grociana) para a satisfação de sua busca por poder". ${ }^{12}$ Assim seus espaços de atuação externa em termos individuais e do aumento de sua projeção no cenário internacional não deveriam ser dificultados por qualquer "partilha de soberania". Como agravante, a corporação diplomática brasileira tem uma visão da Argentina como parceiro menor e as mudanças freqüentes que ocorrem na política externa argentina geram desconfiança.

De forma lateral, a visão progressista desenvolveu-se com pouca influência no interior da diplomacia e de outras agências do governo. Diz respeito a uma visão de

10 Sobre o "desejo de autonomia" e a perspectiva de adesão por parte do Brasil aos regimes internacionais na matriz da política externa brasileira dos anos 90, PINHEIRO (2000), fornece reflexōes interessantes.

11 VIGEVANI, FAVARON, RAMANZINI JR. E CORREIA, op.cit.

12 "grociana" está no próprio artigo. 
acadêmicos e lideranças políticas pró-integração, que propõe um aprofundamento do processo de integração em termos políticos e sociais e que busca abrir espaços para maior institucionalização do bloco. Neste caso coincidem com os progressistas na Argentina.

\section{O caso venezuelano: O giro hacia el sur e as percepções dos atores políticos}

As percepções presentes na Venezuela sobre integração regional são bem diferentes das vistas na Argentina e no Brasil. A recente entrada em curso da Venezuela como membro pleno do Mercosul é resultado de um processo que se iniciou em meados dos anos 90, quando o governo de Rafael Caldera começou a redefinir a estratégia de integração do país, no contexto de uma revisão de sua política externa. Diferentemente dos outros dois países, a Venezuela é um país caribenho e andino, além de amazônico. A Cuenca do Caribe lhe é um espaço vital, sendo uma área de enorme importância geopolítica e geoeconômica onde o país sempre exerceu influência política. É parte da sub-região andina, pois, apesar de apenas três estados fazerem parte da Cordilheira dos Andes, o país está historicamente ligado a esta zona do continente. Os laços históricos com a Colômbia - país com o qual a Venezuela tem uma intensa relação - são às vezes conflitivos, às vezes cooperativos, mas têm um forte conteúdo societal devido às interações crescentes entre suas populações. Por fim, a Venezuela é um país com uma fachada amazônica, certamente a menos desenvolvida, mas que não por isto é pouco relevante. Estas múltiplas identidades explicam em boa medida a política externa venezuelana e, como conseqüência, suas estratégias em matéria de integração e cooperação regionais promovidas pelos governos desde o início da era democrática.

A política externa dos governos venezuelanos entre 1958 e 1998 esteve delimitada pela condição de país ocidental, democrático e petroleiro, que começou a receber importantes recursos desde o primeiro boom do petróleo da década de 1970. Estes fatores determinaram as prioridades geográficas de sua política externa, na qual os Estados Unidos apareciam como um parceiro natural na defesa da democracia e com o qual a Venezuela podia partilhar uma estratégia assistencialista no Caribe com vistas a evitar a expansão do comunismo. Aqueles que apoiavam este enfoque podem ser identificados como conservadores, na medida em que consideravam que a assimetria que gerava a presença dos Estados Unidos limitava a margem de ação em termos de política externa. Por outro lado, um grupo que poderia ser descrito como progressista, considerava que o petróleo era um instrumento que permitia à Venezuela ampliar sua estratégia internacional e apostar em uma maior independência frente aos Estados Unidos.

Em matéria de integração latino-americana e caribenha, os progressistas sempre foram favoráveis à participação do país em iniciativas nas regiōes andina 
e caribenha, nas quais a Venezuela poderia desempenhar uma liderança. Também promoveram a criação de outros mecanismos de cooperação como o Sistema Econômico Latino-Americano - Sela, o Tratado de Cooperação Amazônica, e o Grupo do Rio, no marcos dos quais o país podia estabelecer mecanismos de diálogo e concertação com os maiores países da região, em relação aos quais mantinha prudência quanto a promover iniciativas de integração.

Em matéria econômica, também existiam duas posições que haviam tido influência na política venezuelana de integração com outros países. Por um lado, estavam os ortodoxos, um grupo muito influente, próximo da poderosa Fedecámaras, instituição guarda-chuva do setor privado venezuelano. Este grupo sempre havia sido cético com as propostas de integração latino-americana. Considerava que devido às características peculiares da economia do país, a integração com os países vizinhos não era a melhor opção e, ao invés disto, dever-seia optar pela consolidação das relações com os parceiros extra-regionais tradicionais. Este grupo era especialmente oposto à integração com países vizinhos de maior desenvolvimento industrial que pudessem por em risco o incipiente processo de industrialização que se estava promovendo no país. Frente a este setor, encontravamse os heterodoxos, mais próximos às idéias da Cepal, que consideravam a integração regional como um mecanismo para promover a transformação produtiva na região. Este grupo propunha um tipo de integração com elementos de intervenção pública, que tomasse em conta as assimetrias existentes entre os países da região devido aos diversos níveis de desenvolvimento relativo de cada um.

Conservadores e progressistas, liberais e ortodoxos, atuaram nos marcos do sistema de conciliação de elites descrito por Rey (1983). A política externa venezuelana foi expressão do sistema de conciliação de elites que, no cenário internacional, propunha objetivos similares aos que o Pacto de Punto Fijo buscava a nível doméstico. Isto explica a permanência de metas como o compromisso com a consolidação da democracia, a constante busca da conciliação, do consenso e do compromisso, e a consciência de interdependência, especialmente em relação aos Estados Unidos. Neste contexto, a política de integração buscou um delicado equilíbrio entre a necessidade de satisfazer as demandas dos atores domésticos e de promover a integração latino-americana. Como conseqüência deste processo, a Venezuela entrou mais tarde na Alalc e no Pacto Andino. Apesar do interesse governamental nas duas iniciativas, a adesão do país a elas era rejeitada pelos setores produtivos. Em lugar de optar por uma política de "entrada imposta" à Alalc e ao Pacto Andino, os governos venezuelanos optaram por negociar com os atores em conflito, até conseguir que estes aceitassem a entrada da Venezuela.

O governo de Hugo Chávez produziu um desmoronamento do sistema de consenso das elites. Durante seu período inicial, foi difícil se ter uma percepção meridiana de seu projeto político. Briceño Ruiz argumenta que o chavismo era uma confusa mistura de grupos internos, alguns dos quais estavam inspirados nas idéias bolivarianas e agrupados em torno a um grupo de militares que 
haviam participado do golpe de Estado de 1992; outros estariam vinculados a grupos de extrema esquerda minoritários na Venezuela; e, finalmente, estava um grupo pragmático no qual se incluíam aliados do Movimento Al Socialismo (MAS), velhos políticos e certos setores empresariais. Até 2000, estes três grupos debateram-se internamente para se incluírem no projeto político chavista. Esta confusão manifestou-se na política externa. As velhas tendências conservadoras e progressistas na política externa foram afastadas.

No período entre 1999 e 2001 as tendências existentes no chavismo trataram de influir na política externa. Os militares nacionalistas e os pragmáticos, embora apoiassem objetivos de promoção da ordem multipolar, integração latino-americana e cooperação sul-sul, foram cautelosos em evitar promover um conflito com os Estados Unidos. Os radicais, por sua vez, favoreceram uma política externa mais militante, especialmente no que diz respeito à natureza "estratégica" da integração. Até 2002, nenhum dos setores tinha uma posição hegemônica no desenho e na aplicação da política de integração

Desde o final de 2001 o cenário foi se delimitando com mais clareza. Neste ano, um grupo dos nacionalistas bolivarianos, movimentos políticos como o MAS e setores empresariais distanciaram-se do governo. O setor radical do chavismo começa a se impor, incrementando-se a crítica à ordem mundial e distanciandose dos Estados Unidos. A partir de 2003 Chávez declara seu governo como anti-imperialista e se propõe a desenvolver um projeto político descrito como "Socialismo do Século XXI".

Este processo de definição e redefinição da estratégia internacional de Venezuela manifestou-se em sua política de integração regional. Nos primeiros anos, o Chávez insistia na idéia de criar uma Confederação Latino-Americana, que deveria ter um conteúdo majoritariamente político, e criticava a proposta de criação da Alca. A partir de 2001 anunciava-se a Iniciativa Bolivariana para as Américas (Alba), embora tenha sido somente a partir de 2003 que se começou a delimitar o conteúdo da proposta. A partir de 2004 torna-se clara a estratégia de integração do governo venezuelano, que começa a refletir as reações anti-neoliberais e antinorte-americanas dos grupos "radicais". A ascensão de governos de esquerda no Brasil, Argentina e Uruguai e a decisão dos países andinos de negociar um tratado bilateral de livre comércio com os Estados Unidos determinaram duas decisóes fundamentais que implicaram em uma mudança na estratégia de integração da Venezuela: a sua saída da Comunidade Andina e a solicitação de entrada como membro pleno no Mercosul.

\section{Kirchner, Lula e Chávez pós-2004: novos cenários}

O novo cenário político pós-2004 abriu novas perspectivas para o bloco. A ascensão dos governos de Néstor Kirchner e Lula da Silva, na Argentina e no Brasil, colocou para aqueles da corrente de pensamento progressista a expectativa de aprofundamento do processo de integração com maior articulação econômica, 
mais institucionalização e a construção de uma parceria mais sólida no campo político. Mas já nos dois primeiros anos começaram a aparecer limitações nos comportamentos de ambos.

Neste contexto, Chávez intensifica sua aproximação ao Mercosul e seu crescente afastamento da Comunidade Andina de Naçôes - CAN. Desde a perspectiva do governante venezuelano, tanto Lula quanto Kirchner, representavam uma rejeição ao modelo neoliberal que teria inspirado o Mercosul quando foi criado, assim como um giro no sentido de uma nova integração. Ambos teriam discursos mais próximos do levado adiante por ele na Venezuela, que contrastava com as relações cada vez mais estreitas entre países da CAN - Colômbia e Peru - com os Estados Unidos.

No entanto, chegando o governo Lula a seu segundo mandato, tendo já o governo de Kirchner terminado e dado lugar para a presidência de Cristina Kirchner e estando Hugo Chávez em seu segundo mandato, as perspectivas levantadas em 2003/2004 parecem não ter se concretizado.

$\mathrm{Na}$ Argentina, o governo Kirchner abriu espaços para os pensamentos heterodoxos tanto pragmáticos quanto progressistas, deixando no ostracismo a corrente ortodoxa. ${ }^{13}$ Em relação à economia interna, Kirchner adotou uma estratégia neodesenvolvimentista de caráter heterodoxo, buscando estabelecer uma política industrial mais ativa orientada para a recomposição do parque industrial que se refletiu nas percepçóes do Mercosul. O reflexo desta estratégia econômica no processo de integração navegou entre duas alternativas nos marcos da heterodoxia. Por um lado, recolocou a expectativa do estabelecimento de uma coordenação de políticas macroeconômicas e cambiais com o Brasil, proposta por muitos políticos e acadêmicos. Esta coordenação viria acompanhada de um aumento de eficiência no processo de integração de infra-estrutura e na dimensão institucional para superar um déficit que obstacularizaria uma maior eficiência do bloco. Mas, por outro lado, a adoção de características de um modelo econômico nacionalista e de caráter neodesenvolvimentista junto com o pouco avanço no sentido de organizar políticas para lidar com as assimetrias, deu argumentos a outro grupo no interior da corrente heterodoxa que se preocupa com a dimensão da economia brasileira, e defende o estabelecimento de mecanismos defensivos e de comércio administrado. Esta corrente priorizaria um modelo mais cooperativo que integracionista. Neste caso, o temor de perder espaço em relação ao Brasil em termos regionais aparece claramente.

Nos círculos mais próximos à figura de Kirchner, uma "aliança estratégica" com a Venezuela começou a desenhar-se como um mecanismo equilibrador da construção da liderança brasileira, que aumentaria, por sua vez, os instrumentos de barganha da Argentina. O governo venezuelano dedicou-lhe um caro apoio ao

13 O fim das negociações da Alca comprometeu seus argumentos favoráveis a maior aproximação com os Estados Unidos. 
comprar títulos da dívida argentina exercendo parcialmente o papel de um paymaster que o governo brasileiro evitava assumir. Como elemento a se agregar, uma visão consolidada de política externa de sua gestão não é perceptível e sua preocupação principal é conseguir insumos para o desenvolvimento do país no curto prazo.

No caso brasileiro, as perspectivas também enfrentaram obstáculos. A atuação do governo de Lula no Mercosul vem sendo marcada por movimentos oriundos de distintas correntes de pensamento que compóem o governo. A primeira refere-se à perspectiva autonomista que prioriza a liderança brasileira na América do Sul como um todo, que poderia ser enquadrada segundo a classificação de Myers (1991) no comportamento de "Estado aspirante à hegemonia". Neste caso, a perspectiva da formação de um bloco sul-americano coloca-se como fundamental sendo o Mercosul um instrumento para tal fim. Os esforços orientados para a formação da Comunidade Sul-Americana de Naçôes agora convertida em Unasul são um exemplo desta aspiração. ${ }^{14}$ Em relação ao Mercosul, esta perspectiva impulsionou a assinatura de acordo de associação com os países da CAN e a candidatura da Venezuela a entrar como sócio pleno. Ao mesmo tempo, busca manter um equilíbrio econômico no bloco que favoreça os projetos brasileiros de desenvolvimento industrial e projeção econômica. A segunda corrente, ligada ao Partido dos Trabalhadores, diz respeito à visão de acadêmicos e políticos pró-integração, e sugere o aprofundamento institucional do processo de integração nos campos político e social.

Mas além das forças que compõem o governo Lula, o fator mais importante que vem marcando as atuações na gestão é a erosão da coalizão entre institucionalistas pragmáticos e autonomistas que sustentou os primeiros anos do processo de integração (LIMA, 2006). Com a ruptura da aliança, a posição a ser assumida pelo governo de Lula no campo da integração regional tornou-se mais imprecisa, sujeita a críticas de setores empresariais e de segmentos do aparato governamental de oposição.

Os custos de uma política cooperativa com os parceiros do Mercosul - referente à visão heterodoxa dos argentinos de coordenação de políticas macroeconômicas e aumento de eficiência no processo de integração de infraestrutura - são politicamente difíceis e as iniciativas neste campo são tênues, como no caso do Fundo para a Convergência Estrutural do Mercosul, que embora tenha sido criado é limitado e não atende às expectativas dos demais parceiros. ${ }^{15}$

Dentro deste quadro, a única perspectiva onde houve coincidência de posições na Argentina e no Brasil foi no campo dos progressistas. Embora tenham influência mais limitada nos dois governos, conseguiram alguns ganhos. Para superar o déficit institucional, o Tribunal Permanente de Revisão entrou em vigor e foi

\footnotetext{
14 Celso Amorim (2005) faz um balanço dos dois primeiros anos da política externa do governo de Lula, com muito destaque para a América do Sul. Sobre o Mercosul, a preocupação são seus ganhos frente a outros países da região.

15 Os problemas econômicos regionais no Brasil dificultam uma aceitação política interna de que o país exerça o papel do paymaster na região e absorva custos dos parceiros menores.
} 
criada a Comissão de Representantes Permanentes. Em 2006 foi por fim criado o Parlamento do Mercosul, embora sem poder legislativo.

No caso venezuelano, a polarização e radicalização do conflito político entre finais de 2001 e 2004, e a vitória de Chávez no referendum revogatório realizado no período, produziram uma reconfiguração no interior do chavismo. Os nacionalistas e pragmáticos separaram-se do chavismo e muitos deles passaram às fileiras da oposição. $\mathrm{O}$ controle político do processo foi tomado por radicais. Algo similar ocorreu em matéria econômica, setor no qual os heterodoxos foram substituídos pelos radicais.

O ano de 2004 foi um "cruce de caminos" na política externa de Chávez pois este entendeu sua vitória no referendo como uma autorização para aprofundar o "processo revolucionário" em suas dimensões tanto interna quanto externa. Como assinala González Urrutia, neste ano iniciou-se uma nova etapa da política exterior, manifestada na substituição do esquema tradicional de inserção internacional da Venezuela. "Así, la consolidación del proyecto revolucionario y la conformación de alianzas geopoliticas y estratégicas con otros paises pasaron a ser los ejes centrales de la politica exterior" (GONZÁLEZ URRUTIA, 2006, p.165).

Estes fatores incidiram sobre a estratégia de integração de Chávez, que passou a privilegiar a dimensão política com vistas a criar um bloco de poder que assegurasse aos países sul-americanos poder, autonomia, segurança e influência nos cenários globais. A dimensão econômica da integração passou a estar subordinada à política e era criticada por se considerar uma expressão do "neoliberalismo selvagem" que havia gerado um incremento da dependência regional e não havia podido superar a pobreza e a iniqüidade na região. Desde então, a integração afastou-se da dimensão econômica e comercial e se centrou nos aspectos políticos, ideológicos e militares. A dimensão comercial é abordada desde uma ótica estatista que privilegia as relações entre empresas do Estado e exclui a participação de atores não-estatais, especialmente do setor produtivo. Este seria o início da denominada "integração bolivariana", que busca promover a eqüidade, a igualdade, a lealdade e a unidade de propósitos.

Neste contexto, a entrada ao Mercosul converteu-se em um elemento de sua estratégia de promoção de um mundo multipolar. Os objetivos de política externa do governo coincidiam com alguns elementos da estratégia promovida pelo Mercosul como a rejeição da Alca ou a idéia brasileira de se construir um bloco regional sul-americano mediante a criação da Comunidade Sul-americana de Nações - Casa/Unasul.

Não existe muitas informações sobre como desenvolveu-se o debate no interior do governo sobre a entrada como membro pleno do Mercosul. Não obstante, dois elementos são marcantes. O primeiro deles é a influência dos radicais, que concebiam o Mercosul como elemento central em sua idéia de construir uma ordem "multipolar". Neste enfoque, o Mercosul deveria ser entendido também como um fator de luta contra o neoliberalismo. Por isto, em reiteradas ocasióes o presidente 
venezuelano propôs a necessidade de "reformatar" o Mercosul e convertê-lo em um mecanismo a serviço dos povos. Outro elemento marcante é a crescente marca presidencial no desenho da política de integração.

Neste contexto, o Mercosul converteu-se em uma área de interesse geoestratégico. Havia-se optado por uma política externa agressiva frente aos Estados Unidos e um afastamento cada vez maior dos países andinos, notório inclusive antes do anúncio formal de saída da Venezuela da CAN. O avanço das negociações do Tratado de Livre Comércio entre os Estados Unidos e os países andinos isolou a Venezuela no contexto da CAN, ademais de estar em contradição com objetivos expressos da política exterior do país como a luta contra a ordem unipolar, a cooperação sul-sul e a integração latino-americana. Foi então quando, sob o slogan "nuestro norte es el sur", o governo venezuelano decidiu buscar uma aliança maior com o Mercosul e, em 2005, solicitou a entrada como membro pleno. Foi uma notícia que surpreendeu a políticos, atores econômicos e sociais $\mathrm{e}$, inclusive, acadêmicos pois, apenas um ano antes, havia sido admitido como membro associado do bloco.

\section{Considerações finais}

O novo mandato do governo de Lula e o governo de Cristina Kirchner não introduziram muitas novidades. Por ora, não há perspectivas de aprofundamento da integração do bloco. A política econômica neodesenvolvimentista adotada pelo governo argentino e um novo equilíbrio interno ao bloco resultante da (quase) entrada da Venezuela não favoreceram o avanço pensado em 2003 pelos progressistas. Pelo lado brasileiro, a ruptura na coalizão das correntes existentes no interior do aparato governamental, o peso do Itamaraty nas decisōes em detrimento de setores políticos próximos ao Partido dos Trabalhadores e os avanços autônomos tanto na economia brasileira quanto nas ações pró-ativas do Brasil no cenário internacional, também não contribuíram.

A perspectiva da entrada da Venezuela, cuja política externa está dominada pelos setores radicais, complica ainda mais o cenário regional. A visão destes setores é muito distinta de aquela dos setores dominantes na Argentina e no Brasil. Dois aspectos são particularmente problemáticos. Um deles é o discurso anti-capitalista do governo venezuelano. Neste aspecto, as diferenças em relação a Lula e Cristina Kirchner são substantivas, pois embora estes dois governos venham tentando reduzir o traço comercialista do Mercosul propondo uma ampliação de sua agenda, não sugeriram separar-se dos objetivos de inserção internacional e de aplicação de mecanismos de mercado que caracteriza o bloco. Em conseqüência, o discurso anti-capitalista de Chávez parece não ter lugar na estratégia do Mercosul. Inclusive as chamadas do presidente venezuelano no sentido de reformatar o Mercosul para torná-lo um mecanismo de integração a serviço dos povos, não encontraram apoio 
dentro dos parceiros do bloco. Foram consideradas pouco diplomáticas, dado que a Venezuela é um país ainda em processo de conversão em membro pleno.

Um segundo elemento que pode afetar a formação de uma "percepção comum" dentro do Mercosul diz respeito às relações externas do bloco. As relações conflituosas de Chávez com os Estados Unidos, seus conflitos intermitentes com líderes europeus, ou as tensões com países sul-americanos como Colômbia e Peru, são um problema que Mercosul terá que encarar. O Mercosul é uma união aduaneira que está negociando com a UE e com outros países. Também subscreveu um acordo de livre comércio com os países andinos. Ademais, não ter uma agenda de negociações comerciais com os Estados Unidos pode tornar-se um entrave considerando que Washington reorganizou boa parte de suas relações comerciais com a América Latina por meio dos tratados de livre comércio. Neste contexto, resulta complexo como compatibilizar a agressiva política externa venezuelana com a estratégia comercial externa do Mercosul.

Por fim, cabe ressaltar a importância do impacto das idéias na formulação do comportamento dos três países frente ao processo de integração. Se tomamos em conta as divisões e percepções internas existentes nestes países que incidiram sobre a evolução do Mercosul podemos encontrar algumas explicações para a distância entre discurso e ação, para a paralisia do bloco em alguns períodos de sua história, para as dificuldades para se estabelecer um marco mais institucional. Por outro lado, os interesses também demonstraram sua influência persistente no destino do Mercosul. As idas e vindas nas prioridades estratégicas da Argentina e do Brasil, o impacto do comportamento argentino no compromisso em relação à importância do bloco regional, ou a percepção da forma como o Mercosul pode ser útil na reconfiguração das relações com potências ou outros blocos regionais, foram variáveis que, sem dúvida, tiveram um impacto na evolução do bloco.

\section{Referências bibliográficas}

AMORIM, Celso (2005) A politica externa do governo Lula: os dois primeiros anos, publicado em OPSA/Iuperj [http://obsevatorio.iuperj.br/analises.php]. Disponibilidade: 25/04/2009.

BLYTH, M. (2003) Structures Do Not Come with an Instruction Sheet: Interests, Ideas, and Progress in Political Science. Perspectives on Politics vol.1 n.4, dez., p.695-706.

BRICEÑO RUIZ, J. (2000) Il Venezuela di Chávez. Tra sogni bolivaristi e realismo geopolítico. Limes. Rivista Italiana de Geopolitica n.2, p. 85-95.

CARDOSO DA SILVA, E. (1998) Cuarenta años después: la política exterior que tuvimos y la que necesitamos. Revista Venezolana de Análisis de Coyuntura vol. IV n.1, p.44.

CHUDNOVSKY, D. e LÓPEZ, A. (2000) A evolução do debate sobre o papel do Mercosul na estratégia de desenvolvimento econômico da Argentina. In J.Campbell (org.), Mercosul: entre a realidade e a utopia. Rio de Janeiro: Relume Dumará, p.295-352. 
GOLDSTEIN, J. e KEOHANE, R. (1993) Ideas and foreign policy-beliefs, institutions and political change. London: Cornell University Press, p.3-30.

GONZÁLEZ URRUTIA, E. (2006) Las dos etapas de la política exterior de Chávez. Nueva Sociedad n.205, set/out.

LAVAGNA, R. (1997) Mercosur: consistencia densa o leve?. In: O Mercosul e a Integração Sul-Americana: mais do que a economia. Encontro de culturas. Brasília: Funag, p.61-82.

LIMA, M.R.S. de. Decisóes e Indecisóes: um balanço da política externa do primeiro governo do presidente Lula, 2006. Publicado por OPSA/Iuperj [http://observatorio.iuperj.br/artigos_ resenhas.php]. Disponibilidade: 25/04/2009.

MALAMUD, A. e SCHMITTER, P. (2006). La experiencia de integración europea y el potencial de integración del Mercosur. Desarrollo Económico vol.46 n.181. Buenos Aires, junho.

MALAMUD, A. e CASTRO, P. (2007) Are Regional Blocs leading from nation states to global governance? A skeptical vision from Latin America. Iberoamericana. Nordic Journal of Latin American and Caribbean Studies vol.37 n.1.

MYERS, D. (1991). Threat perception and strategic responses of regional hegemons: A conceptual overview. In: D.Myers (org.), Regional Hegemons: Threat perceptions and strategic responses. San Francisco: Westview Press.

MORAVCSIK, A. (2001) Bringing Constructivist Integration Theory of EU out of the Clouds: Has it Landed Yet?, European Union Politics vol.2 n.2, p.219-249.

PINHEIRO, L. (2000) Traídos pelo desejo: um ensaio sobre a teoria e a prática da política externa brasileira contemporânea. Contexto Internacional vol.22 n.2, p.305-336.

REY, J.C. (1983) El sistema político venezolano y los problemas de su política exterior. In: Instituto de Estudios Políticos de la Universidad Central de Venezuela, La agenda de la política exterior de Venezuela. Caracas: IEP-UCV.

RUSSELL, R. e J.TOKATLIAN. El lugar de Brasil en la politica exterior argentina. Buenos Aires: Fondo de Cultura Econômica, 2003, 123 p.

Veiga, P. da M. (2002). O policy making da política comercial no Brasil: os caminhos da transição. In: El proceso de formulación de la política comercial. Nivel uno de um juego de dos niveles: Estudios de paises em el Hemisfério Occidental. Banco Interamericano de Desarrollo/ Munk Centre/ Inter-American Dialogue, March. (Documento de divulgação 13)

VIGEVANI, T., MARIANO, K.L.P e Mariano, M.P. (2001) Brasil e integração regional: Mercosul e Alca. São Paulo: Cedec.

VIGEVANI, Tullo et al. O papel da integração regional para o Brasil: universalismo, soberania e percepção das elites. Rev. bras. polít. int., Brasília, v. 51, n. 1, 2008. Available from <http://www.scielo.br/scielo.php?script=sci_arttext $\&$ pid $=$ S0 034 $73292008000100001 \& \operatorname{lng}=e n \& n r m=i s o>$. access on 02 April 2009. doi: 10.1590/S003473292008000100001 . 


\section{Resumo}

No artigo, analisam-se as percepções de atores políticos domésticos no interior dos maiores países membros do Mercosul sobre o processo de integração, e apresentam-se as idéias existentes na esfera pública de apoio ou de rejeição ao bloco. Para atingir este objetivo, são analisadas as idéias defendidas por estes atores na Argentina e no Brasil, assim como é avaliada a medida na qual atores políticos domésticos da Venezuela são envolvidos no processo de incorporação do país ao Mercosul.

\section{Abstract}

The article analyses perceptions of domestic political actors about the integration in Mercosur inside each of its biggest members, and presents some ideas for and against the block. To achieve this aim, it analyses ideas defended by these actors in Argentina and Brazil and evaluates how domestic actors in Venezuela were involved in the process of incorporation of this country to Mercosur.

Palavras-chave: Mercosul, integração sul-americana, idéias em política externa. Key words: Mercosur, south american integration, ideas on foreign policy. 